EGU21-7200

https://doi.org/10.5194/egusphere-egu21-7200

EGU General Assembly 2021

(c) Author(s) 2021. This work is distributed under

the Creative Commons Attribution 4.0 License.

\title{
Assessing the wildfire activity in protected areas of the Amazon basin
}

\author{
Emmanuel Da Ponte ${ }^{1}$, Fermin Alcasena ${ }^{2}$, Tejas Bhagwat ${ }^{3}$, and Zhongyang $\mathrm{Hu}^{4}$ \\ ${ }^{1}$ German Aerospace Center (DLR), Lax, Wesseling, Germany (emmanuel.daponte@dlr.de) \\ ${ }^{2}$ United States Department of Agriculture (USDA) Forest Service, Oregon State University, 321 Richardson Hall, Corvallis, OR \\ 97331, United Sates,(ferminalcasena@gmail.com) \\ ${ }^{3}$ University of Goettingen, Department of Conservation Biology, Bürgerstrasse 50, 37073, Goettingen/Germany, \\ (tejas.bhagwat@biologie.uni-goettingen.de) \\ ${ }^{4}$ Institute for Marine and Atmospheric Research, Ultrecht University, Ultrecht, Netherlands, (z.hu@uu.nl)
}

Despite growing concerns regarding the Amazonian wildfires, the magnitude of the problem is poorly understood. In this study, we assessed the wildfire activity in the protected natural sites $(n=428)$ of Bolivia, Brazil, Colombia, Ecuador, French Guyana, Guyana, Peru, Suriname, and Venezuela, encompassing an area of 1.4 million $\mathrm{km}^{2}$ of the Amazon basin. A $250 \mathrm{~m}$ resolution spectroradiometer sensor imaging (MODIS) was used to obtain land-use/land-cover (MODIS land use land cover product) changes and derive the wildfire activity data (ignition locations and burned areas (MODIS active fire products)) from 2001 to 2018. First, we characterized the mean fire return interval, wildfire occurrence, and empiric burn probability. Then, we implemented a transmission analysis to assess the burned area from incoming fires. We used transmission analysis to characterize the land use and anthropic activities associated to fire ignition locations across the different countries. On average, $867 \mathrm{~km}^{2}$ of natural forests were burned in protected natural sites annually, and about 85 incoming fires per year from neighboring areas accounted for $10.5 \%(9,128$ ha) of the burned area. The most affected countries were Brazil (53\%), Bolivia (24\%), and Venezuela (16\%).Considerable amount of fire ignition points were detected in open savannas (29\%) and grasslands (41\%), where the fire is periodically used to clear extensive grazing properties. The incoming fires from savannas were responsible for burning the largest forest areas within protected sites, affecting as much as 9,800 ha in a single fire event. In conclusion, we discuss the potential implications of the main socioeconomic factors and environmental policies that could explain increasing trends of burned areas. Wildfire risk mitigation strategies include the fire ignition prevention in developed areas, fire use regulation in rural communities, increased fuels management efforts in the buffer areas surrounding natural sites, and the early detection system that may facilitate a rapid and effective fire control response. Our analysis and quantitative outcomes describing the fire activity represent a sound science-based approach for an well defined wildfire management within the protected areas of the Amazonian basin. 